\title{
Valuasi ekonomi Setu Pedongkelan, Kota Depok, Jawa Barat (pemanfaatan sumber daya perikanan)
}

\author{
Gusti Ayu Dwi Wulandari \\ Prodi DIII PBB/Penilai Jurusan Perpajakan Politeknik Keuangan Negara STAN
}

\begin{abstract}
This study aims to identify the types of utilization found in Setu Pedongkelan and estimate the economic value of Setu Pedongkelan through fisheries utilization. The use of fisheries in Setu Pedongkelan is capture fisheries. The data used in this research are primary data in the form of survey results, interviews and online questionnaires as well as secondary data obtained from the documentation archive. The method used in this research is the market price method. The results of the study found that the types of utilization found in Setu Pedongkelan include direct use such as fisheries, irrigation and recreation. In addition, there are also indirect uses such as places for biota to find food, flood control, spawning, conservation and places or research facilities. This research also gives the result that the economic value of Setu Pedongkelan from fisheries utilization is IDR 2,472,960,000.
\end{abstract}

Keywords: Valuation, Capture Fisheries, Market Price Method, Economic Value

\begin{abstract}
Abstrak
Penelitian ini bertujuan untuk mengidentifikasi jenis-jenis pemanfaatan yang terdapat pada Setu Pedongkelan dan mengestimasi nilai ekonomi dari Setu Pedongkelan melalui pemanfaatan perikanan. Pemanfaatan perikanan di Setu Pedongkelan adalah perikanan tangkap. Data yang digunakan dalam penelitian adalah data primer berupa hasil survei, wawancara dan kuesioner online serta data sekunder yang didapatkan dari arsip dokumentasi. Metode yang digunakan dalam penelitian ini adalah metode harga pasar. Hasil penelitian menemukan bahwa jenis-jenis pemanfaatan yang terdapat di Setu Pedongkelan diantaranya adalah pemanfaatan secara langsung seperti perikanan, irigasi dan rekreasi. Selain itu, terdapat juga pemanfaatan tidak langsung seperti tempat biota mencari makan, pengendali banjir, pemijahan, konservasi dan tempat atau sarana penelitian. Penelitian ini juga memberikan hasil bahwa nilai ekonomi Setu Pedongkelan dari pemanfataan perikanan yaitu sebesar $\mathrm{Rp} 2.472 .960 .000$.
\end{abstract}

Kata Kunci: Valuasi, Perikanan Tangkap, Metode Harga Pasar, Nilai Ekonomi

\section{PENDAHULUAN}

Situ adalah istilah dalam bahasa Sunda yang dapat diartikan sebagai danau alam atau dapat juga merupakan danau buatan. Sedangkan, warga Betawi menyebut situ sebagai setu, yaitu wadah genangan air di atas permukaan tanah yang terbentuk secara alami atau buatan di mana sumber airnya berasal dari mata air, air hujan dan/atau limpasan air permukaan.

Dalam Peraturan Presiden No. 54 Tahun2008 tentang Penataan Ruang Kawasan Jabodetabekjur, setu didefinisikan sebagai suatu wadah tampungan air di atas permukaantanah, yang terbentuk secara alami maupun buatan yang airnya berasal dari tanah atau airpermukaan sebagai suatu siklus hidrologis, yang merupakan salah satu bentuk kawasanlindung. 
Peraturan Pemerintah No. 26 tahun 2008 tentang Rencana Tata Ruang Wilayah Nasional menjelaskan bahwa fungsi kawasan Setu dibagi menjadi kawasan sekitar Setu yang berfungsi sebagai kawasan perlindungan setempat dan kawasan resapan air yang berfungsi sebagai kawasan memberikan perlindungan kawasan bawahnya. Untuk kawasan sekitar Setu ditetapkan dengan kriteria suatu wilayah daratan dengan jarak 50 (lima puluh) sampai dengan 100 (seratus) meter dari pasang tertinggi atau daratan di sepanjang tepian Setu yang lebarnya poposional terhadap bentuk dan kondisi fisik Setu.

Saat ini, jumlah setu yang berada di Kota Depok semakin berkurang. Salah satu penyebabnya adalah pengalihan fungsi lahan setu menjadi lahan tempat tinggal atau residensial. Selain itu, banyak pula kawasan setu di Kota Depok yang masih kurang terpelihara dan terjaga kelestariannya. Untuk itu, demi mengembalikan fungsi setu kepada fungsi awalnya, pemerintah serta masyarakat harus turut berkontribusi dalam upaya konservasi agar setu kembali terpelihara dan keberlanjutan kelestariannya.

Keberadaan kawasan Setu Pedongkelan di Kecamatan Cimanggis, Kota Depok saat ini tengah dalam perhatian pemerintah baik Pemerintah Kota Depok maupun Pemerintah DKI Jakarta. Setu Pedongkelan terletak di antara perbatasan antara Kota Depok dan DKI Jakarta, sehingga masing-masing pemerintah kota harus bekerjasama untuk menjaga kelestarian dari kawasan Setu Pedongkelan.

Setu Pedongkelan saat ini dapat dijadikan destinasi andalan para wisatawan terutama masyarakat Kelurahan Tugu di Kota Depok dan Kelurahan Pasar Rebo di Jakarta Timur. Hal ini karena kawasan Setu Pedongkelan masih memiliki keindahan alam dan potensi perikanan yang cukup banyak. Namun, kenyataannya adalah kawasan Setu Pedongkelan masih kurang diketahui keberadaannya oleh masyarakat di luar Kelurahan Tugu dan Kelurahan Pasar Rebo. Oleh sebab itu, dilakukanlah penilaian ekonomi dari Setu Pedongkelan.

Penelitian ini dilakukan untuk mengetahui jenis-jenis pemanfataan yang terdapat di Setu Pedongkelan. Selain itu, penelitian ini juga dilakukan untuk memperoleh nilai ekonomi dari Setu Pedongkelan melalui perikanan. Tujuan tersebut diharapkan dapat menjadi salah satu informasi serta bahan pertimbangan bagi Pemerintah dan masyarakat pengelola untuk menentukan kebijakan-kebijakan yang tepat dalam menjaga kelestarian Setu Pedongkelan.

\section{METODE PENELITIAN \\ Lokasi dan Waktu Penelitian}

Penelitian ini dilaksanakan di kawasan Setu Pedongkelan yang terletak di perbatasan antara wilayah Depok dan wilayah Jakarta Timur. Secara administratif, Setu Pedongkelan berada di Jalan Setu Pedongkelan, Kelurahan Tugu, Kecamatan Cimanggis, Kota Depok, Provinsi Jawa Barat. Lokasi ini dipilih karena lokasi yang berdekatan dengan peneliti dan akses yang mudah dicapai serta belum adanya penelitian terdahulu mengenai lokasi ini. Penelitian ini telah dilakukan selama 3 minggu pada bulan Juli 2020.

\section{Alat dan Obyek Penelitian}

Penelitian ini menggunakan alat berupa handphone, komputer, alat tulis, dan kuesioner online. Obyek dari penelitian ini adalah kawasan Setu Pedongkelan dengan luas wilayah sebesar 6,25 hektar dan para nelayan perikanan tangkap di Setu Pedongkelan. 


\section{Penentuan Sampel}

Sampel yang digunakan adalah sebanyak 27 orang/responden yang tergabung dalam Komunitas Mancing Areman.

\section{Jenis dan Analisis Data}

Dalam penelitian ini, jenis data yang dibutuhkan adalah data primer dan data sekunder. Data primer didapatkan melalui kegiatan mengunjungi objek penelitian untuk mengamati secara langsung ekosistem, potensi sumber daya alam dan keadaan lingkungan dari objek penelitian serta melakukan wawancara secara langsung serta dengan bantuan kuesioner online kepada sejumlah responden. Sedangkan data sekunder didapatkan dari arsip dokumentasi baik secara fisik (hardfile) ataupun berupa softfile. Data sekunder yang didapatkan dapat berupa luas objek penelitian dan keadaan-keadaan objek penelitian yang sesuai dengan topik penelitian.

Analisis data dilakukan dengan metode harga pasar (real market price). Metode ini menggunakan harga pasar yang sesungguhnya. Penentuan sampel untuk nelayan perikanan tangkap dilakukan dengan wawancara dan metode simple random sampling terhadap anggota Komunitas Mancing Areman mengenai jumlah ikan yang dapat mereka tangkap pada rata-rata sehingga dapat ditentukan pendapatan dan biaya berdasarkan harga pasar dari kegiatan perikanan tersebut. Secara keseluruhan dapat dihitung dengan rumus:

$$
\begin{aligned}
\text { Keuntungan } & =\text { Pendapatan }- \text { Biaya } \\
N E P & =M B_{N T} x Q_{N T}
\end{aligned}
$$

Keterangan :

NEP : Nilai Ekonomi Perikanan

$\mathrm{MB}_{\mathrm{NT}} \quad$ : Manfaat Bersih (keuntungan rata-rata nelayan tangkap) (Rp/kg)

$\mathrm{Q}_{\mathrm{NT}} \quad$ : Jumlah Pemancing (Orang/Tahun)

\section{HASIL DAN PEMBAHASAN}

\section{Jenis-Jenis Pemanfaatan Setu Pedongkelan}

Setu Pedongkelan merupakan setu alami yang sudah ada sejak lama. Setu ini memiliki wilayah yang sejuk dengan potensi perikanan yang dapat dikatakan selalu cukup. Pada tahun 2014, Setu Pedongkelan mengalami pendangkalan dan semenjak itu pemerintah dan masyarakat saling bekerja sama untuk memperbaiki kerusakan yang terjadi pada Setu Pedongkelan.

Pemerintah telah menetapkan berbagai aturan mengenai pemanfaatan di Setu Pedongkelan. Hal tersebut harus selalu dipatuhi oleh masyarakat sekitar ataupun para wisatawan. Pemanfataan yang dapat dilakukan atau berada di kawasan Setu Pedongkelan antara lain pemanfaatan secara langsung dan pemanfaatan secara tidak langsung. Pemanfaatan langsung di antaranya adalah pemanfaatan perikanan, pemanfaatan irigasi dan pemanfaatan rekreasi. Dalam hal pemanfaatan perikanan, pemerintah sudah menetapkan larangan terhadap penggunaan jaring atau pengelolaan keramba. Sehingga, alat yang digunakan oleh para nelayan hanyalah alat pancing sederhana dan kegiatan yang terjadi dalam pemanfaatan perikanan adalah kegiatan perikanan tangkap.

Lalu untuk pemanfaatan tidak langsung yang terdapat di Setu Pedongkelan dapat dilihat dengan manfaat fungsional dari proses ekologi sumberdaya Setu Pedongkelan yang di antaranya yaitu tempat biota mencari makan, pengendali banjir, pemijahan, konservasi dan tempat atau sarana penelitian. 


\section{Karakteristik Responden}

Melalui wawancara langsung dan kuesioner online terdapat 27 orang responden yang semuanya berjenis kelamin laki-laki. Hasil wawancara langsung dan kuesioner online tersebut menginformasikan bahwa terdapat 9 responden yang menyatakan bahwa mereka melakukan kegiatan perikanan tangkap dengan tujuan profesi utama ataupun profesi sampingan, sedangkan 18 orang lainnya menyatakan bahwa mereka melakukan kegiatan perikanan tangkap hanya sekedar hobi atau mengisi waktu luang. Rata-rata umur responden yang melakukan kegiatan perikanan tangkap adalah 41 tahun dengan distribusi sesuai dengan gambar 1 .

\section{PERSEBARAN UMUR}

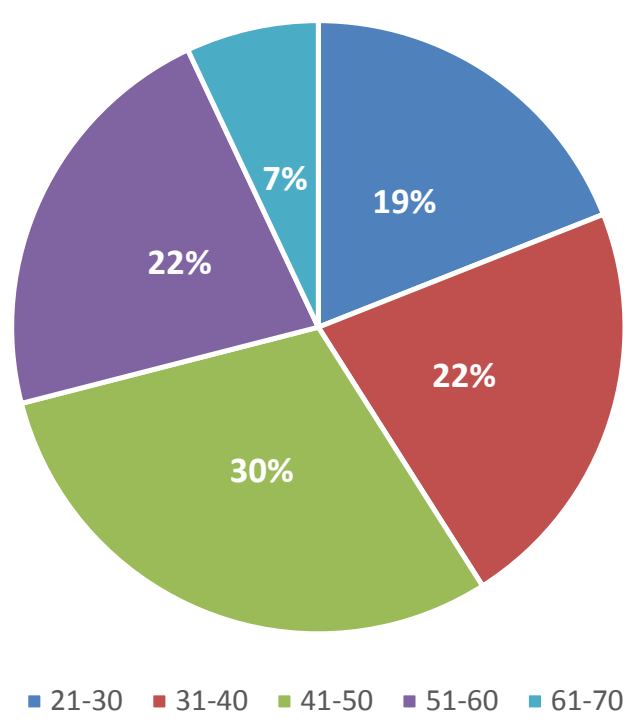

Gambar 1. Sebaran Umur Responden

Dari gambar 1 di atas dapat dilihat bahwa responden dari nelayan perikanan tangkap terbesar yaitu usia 41-50 tahun sebanyak 8 orang (30\%), dan yang paling sedikit yaitu usia 61-70 tahun sebanyak 2 orang (7\%). Untuk usia 21-30 hanya 5 orang (19\%), hal ini karena terdapatnya mitos di kawasan Setu Pedongkelan bahwa pantang lelaki dewasa berusia 21-25 tahun untuk memancing di sekitar Setu Pedongkelan. Lalu sisanya adalah usia 31-40 tahun dan 51-60 tahun yang jumlahnya sama yaitu 6 orang (22\%). Dari hasil data responden didapatkan pula informasi bahwa pemancing biasanya menghabiskan waktu beragam mulai dari 4 jam hingga 12 jam dalam melakukan kegiatan perikanan tangkap.

\section{Pendapatan}

Dengan rata-rata kegiatan perikanan tangkap yang dilakukan sebanyak 3 - 4 kali per minggu atau kurang lebih 206 kali per tahun, para nelayan perikanan tangkap di Setu Pedongkelan dapat memperoleh pendapatan kotor yang beragam sesuai dengan jenis ikan yang mereka dapat pada setiap kegiatan perikanan tangkap. Oleh sebab itu, peneliti mengestimasi rata-rata dari perolehan jumlah ikan per kg dari 27 responden per minggunya lalu dikali dengan 48 (jumlah minggu dalam setahun) untuk disetahunkan. Setelah itu, masing-masing perolehan jumlah ikan berdasarkan jenisnya dikalikan dengan harga pasar dari jenis ikan tersebut. Harga pasar yang didapatkan adalah harga konsumen. Harga tersebut didapatkan melalui wawancara langsung para pedagang ikan. Untuk lebih jelasnya dapat dilihat pada tabel 1. 
Tabel 1.Pendapatan dari Kegiatan Perikanan Tangkap per Orang

\begin{tabular}{clccc}
\hline No. & Uraian & Harga $(\mathbf{R p} / \mathbf{K g})$ & $\begin{array}{c}\text { Jumlah } \\
(\mathbf{R p} / \text { Tahun })\end{array}$ & $\begin{array}{c}\text { Nilai } \\
(\mathbf{R p} / \text { Tahun })\end{array}$ \\
\hline 1. & Mujair/Nila & 30.000 & 126.22 & 3.786 .000 \\
2. & Gabus & 80.000 & 32.18 & 2.574 .000 \\
3. & Lele & 25.000 & 30.04 & 751.000 \\
4. & Emas & 35.000 & 24.71 & 864.000 \\
5. & Bawal & 25.000 & 19.91 & 497.000 \\
6. & Patin & 25.000 & 22.22 & 555.000 \\
\hline Total Penerimaan & & & $\mathbf{9 . 0 2 7 . 0 0 0}$ \\
\hline
\end{tabular}

\section{Biaya-Biaya}

Sering tidaknya kegiatan memancing bukanlah pengaruh utama terhadap jumlah ikan $(\mathrm{kg})$ yang didapatkan. Hal ini karena jumlah ikan yang didapat juga bergantung pada umpan dan alat yang digunakan, yang menunjukkan adanya pengeluaran atau biaya. Rata-rata biaya yang dikeluarkan oleh pemancing yaitu sebesar Rp 8.805.000 per tahun. Masing-masing nelayan memiliki keperluan ataupun kemampuan pembelian alat dan barang yang jumlahnya berbeda-beda sehingga akhirnya terdapat keberagaman dari jumlah biaya mingguan serta tahunan.

Oleh sebab itu, dengan memperoleh data mengenai biaya yang dikeluarkan masing-masing responden, peneliti mengestimasi rata-rata pengeluaran atau biaya per tahun dari setiap variabelnya sesuai pada tabel 2.

Tabel 2. Biaya Variabel dan Biaya Tetap dari Kegiatan Perikanan Tangkap per Orang

\begin{tabular}{|c|c|c|c|}
\hline Biaya Variabel & & & \\
\hline Umpan & 1.626 .000 & Transportasi & 320.000 \\
\hline Lumut & 1.004 .000 & Lainnya & 5.608 .000 \\
\hline Total Biaya Variabel & & & 8.558 .000 \\
\hline Biaya Tetap & & & \\
\hline Penyusutan Alat Pancing & & & 245.000 \\
\hline Total Biaya Tetap & & & 245.000 \\
\hline
\end{tabular}

\section{Nilai Ekonomi Perikanan di Setu Pedongkelan}

Untuk mengetahui nilai ekonomi Setu Pedongkelan melalui perikanan yang pertama harus didapatkan adalah nilai dari manfaat bersih dengan rumus pendapatan dikurangi total biaya variabel dan total biaya tetap, hasilnya sebesar Rp 224.000. Lalu setelah itu dicari jumlah nelayan perikanan tangkap per tahunnya untuk dikali dengan manfaat bersih. Informasi mengenai jumlah nelayan perikanan tangkap per tahunnya didapatkan melalui wawancara langsung kepada nelayan yang melakukan kegiatan perikanan tangkap sebanyak $5-7$ kali per minggu. Hal ini karena mereka lebih mengetahui keadaan di kawasan Setu Pedongkelan setiap harinya. Mereka memberikan informasi bahwa pada hari senin dan jumat, jumlah nelayan sebanyak 20 orang, pada selasa - kamis sebanyak 30 orang dan pada sabtu - minggu sebanyak 50 orang yang jika dijumlah maka dalam setahun (48 minggu) terdapat 11.040 nelayan perikanan tangkap di Setu Pedongkelan. Sehingga, diperoleh nilai ekonomi Setu Pedongkelan melalui perikanan yaitu sebesar Rp 2.472.960.000/tahun.

\section{KESIMPULAN DAN SARAN Kesimpulan}

Berdasarkan hasil dan pembahasan di atas, maka dapat diambil beberapa kesimpulan. Jenis-jenis pemanfaatan yang terdapat di Setu Pedongkelan adalah pemanfaatan secara langsung seperti perikanan, irigasi dan rekreasi. Selain itu, terdapat 
juga pemanfaatan tidak langsung seperti tempat biota mencari makan, pengendali banjir, pemijahan, konservasi dan tempat atau sarana penelitian. Kemudian, nilai ekonomi dari Setu Pedongkelan yang dihitung melalui pemanfaatan perikanan yaitu perikanan tangkap sebesar Rp 2.472.960.000/tahun.

\section{Saran}

Dari hasil penelitian ini terdapat beberapa saran mengenai pengelolaan setu saat ini dan pada masa yang akan datang agar pemanfaatan dapat optimal dan berkelanjutan. Pertama, pemerintah perlu memperhatikan penyediaan fasilitas yang baik pada pemanfaatan rekreasi, perikanan tangkap dan fasilitas untuk pemanfaatan lainnya untuk meningkatkan kenyamanan pengunjung serta nelayan perikanan tangkap juga menunjukkan adanya tanggung jawab dari pemerintah sebagai pengelola Setu Pedongkelan. Kedua, masyarakat perlu menjaga dan merawat kawasan Setu Pedongkelan dengan lebih giat dan perlu diperketatnya peraturan terhadap para pelanggar yang merusak kelestarian Setu Pedongkelan. Ketiga, perlunya peran aktif dari tokoh masyarakat atau para pemuka yang dihormati di masyarakat dalam memberikan pemahaman tentang nilai-nilai yang terdapat dalam Setu Pedongkelan agar terdapat tekad yang erat antar masyarakat untuk terus menjaga kelestarian Setu Pedongkelan. Keempat, penelitian yang disarankan untuk dilanjutkan yaitu valuasi atau penilaian terhadap nilai-nilai lain seperti pemanfaatan irigasi, pemanfaatan rekreasi, pemanfataan pengendali banjir dan lainnya sehingga didapatkan nilai total seluruh pemanfaatan yang ada pada Setu Pedongkelan.

\section{DAFTAR PUSTAKA}

Widyaningsih, P. (2015). Penilaian Ekonomi Setu Gede, Kelurahan Setu Gede, Kecamatan Bogor Barat, Kota Bogor. Skripsi. FEM, Ekonomi Sumberdaya dan Lingkungan, Institut Pertanian Bogor, Bogor.

Arniawati, Kasim, S., Anshar, R. Analisis Jasa Lingkungan Ekowisata Air Terjun Lahundape di Kawasan Tahura Nipa-Nipa. Jurnal Ecogreen, 3(1), 27-31.

BPS. (2019). Kecamatan Cimanggis Dalam Angka. Depok: BPS Depok

Simanjorang, L., Banuwa, I., Safe'i, R., \& Setiawan, A. (2018). Valuasi Ekonomi Air Terjun Sipiso-piso dengan Travel Cost Method dan Willingness To Pay. Jurnal Silva Tropika, 2(3).

Ismail, Ahyar. (2016). Nilai Manfaat Ekonomi Dan Pengelolaan Waduk (Studi Kasus Waduk Ir. H. Juanda). Prosiding Seminar Nasional Lahan Basah, Jilid 1, 408414.

Asnil. (2012). Analisis Penilaian Ekonomi Dan Kebijakan Pemanfaatan Sumberdaya Danau Yang Berkelanjutan (Studi Kasus Danau Maninjau Sumatera Barat). Disertasi. Sekolah Pascasarjana, Institut Pertanian Bogor, Bogor.

Halomoan, H. (2012). Valuasi Ekonomi Danau Sentani Di Kabupaten Jayapura. Jurnal Ecotrophic. 7(2). 135-144.

Irwan. (2018). Luas Setu Pedongkelan Dihitung Kementerian. Diakses pada 31 Juli 2020 melalui https://www.radardepok.com/2018/05/luas-Setu-pedongkelandihitung kementerian/.

Puspita, L., Ratnawati, E., I Nyoman, N \& Meutia, A. Bab 7 Setu dan Embung. Diakses pada 31 Juli 2020 melalui https://konservasiSetudepok.wordpress.com/buku-tentangSetu/lani-puspita-dkk2/\#: :text=Setu\%20adalah\%20wadah\%20genangan\%20air,dan\%2 Fatau\%20limpasan\%20air\%20permukaan.

Wahyudi, Agung. (2015). "Eco Park" Sebagai Upaya Pencegahan Banjir Ibu Kota Jakarta Dan Sarana Pariwisata (Studi Kasus: Setu Pedongkelan Depok, Jawa Barat). Proceedingsof The 2nd ECO-Architecture Conference (EAC 2)

Sofiana, Solichin, A., Wijayanto, D. (2016). Valuasi Ekonomi Manfaat Langsung Dan Tidak Langsung Kawasan Waduk Malahayu, Kabupaten Brebes. Diponegoro Journal Of Maquares, 5(3), 119-126. 